\title{
Research on the Dilemma and Countermeasures of the National Social Work Education in Chinese Colleges and Universities
}

\author{
GuangHan Zhou a, TongZhu Xu \\ School of Hubei University for Nationalities, Enshi 445000, China. \\ a373925797@qq.com
}

Keywords: National social work education; dilemma; countermeasure

\begin{abstract}
National social work is a process to provide professional services to minorities with professional social work concepts, theories and methods. However, in the education of social work, national social work education, namely social work academic education related to nations and culture and continuing education are not paid enough attention to, and the development is relatively slow. China is a unified multi-ethnic country, and the national social work education has great possibility and urgency. In consequence, we should learn from the experience of overseas and overseas social work education. The research and practice of national social work have begun since the 20th century. Up to now, there are some colleges and universities in the country having set up social work professional, and there are master and doctoral points of social work in ethnic areas. However, there are still many difficulties in the national social work education. Due to the relative lag of the practice and research of national social work in domestic, the development of national social work education is relatively backward. At present, there is no training base for national social workers, and the continuing education courses all lack ethnic and cultural sensitivity. In addition, the contents and materials of occupation qualification examination of social work do not involve the ethnic and cultural contents. The relevant government department's top-level design, practice field, academic and education circles independently and consciously improve the social work field ethnic and cultural sensitivity is the path for our national social work education to better and faster develop
\end{abstract}

\section{Introduction}

The purpose of this study and the problems to be solved are: through the research on overseas and domestic ethnic social work education, to discuss current situation, problems and countermeasures of Chinese national social work education and continuing education. The significance of this study in theory is: on the one hand, it is hoped that the education problem of national social work education are discussed together by more people in education, practice, and academics. On the other hand, it is expected that this paper can make a little contribution to the national social work education concept, development path and specific course design. From these two points, we can better promote the development of social work education in a unified and multi-ethnic Chinese soil, so as to achieve localization and specialization. The practical significance of this study is: on the one hand, to explore the national social work education has great significance for the cultivation of local, pragmatic, cultural sensitivity and national sensitivity social workers. On the other hand, explorations on national social work education will also provide various services and support for students in different ethnic groups, different age and different countries.

\section{Dilemma faced by the development of national social work education -- a survey based on} G school

\subsection{A summary of G school national social work education and the sample characteristics of the survey}

G school is a normal university in the South China minority areas. Since 2011, G school has set up a social work undergraduate major, and in the same year, it recruited community management class (only 1 grade). In 2009, it began to recruit social work masters [1]. Since 2001, there have been 
a certain number of students from minority areas in the social work undergraduate and graduate students enrolled in $\mathrm{G}$ school. In addition, a certain proportion of social work graduates engaged in social work professional practice. Since 2001, in G school social work professional courses, national courses are set, including "Introduction to Chinese Nation", "Ethnic Sociology", "Chinese Culture introduction", "Cultural Anthropology", "National Social Work", "Classic Readings in Anthropology" and so on [2]. What's more, there are students choosing the paper related to national social work as a graduation thesis to study.

In order to further study the dilemma faced by the development of national social work education, we chose $G$ school as a case for the analysis. The $G$ school, at present, social work major undergraduate and graduate students are about 200 students. We issued 200 copies of the "National Social Work Education Research" questionnaire to the $G$ school social work undergraduate and master students. 167 questionnaires were recovered, and there were 166 effective questionnaires. In addition, we also interviewed some social work teachers in $\mathrm{G}$ school, and analyzed the text of the $\mathrm{G}$ school social work personnel training program [3].

1. The nation composition of samples

We investigated 165 effective samples, in which the ethnic composition included 8 ethnic groups of Zhuang, Han, Yao, Hui, Tibetan, Yankee family, Dong, and Miao, and its basic structure was shown in the following table [4]. In the 166 valid samples, the Han occupied the majority, accounting for $66.1 \%$; Zhuang was the second, accounting for 23.6\%; and Yao ranked the third, accounting for $5.5 \%$ [5]. According to the nation composition characteristics of the ethnic group that G school was in, the sample is mainly based on the local students.

Table 1. Samples nation composition analysis

\begin{tabular}{|c|c|c|c|c|}
\hline & Frequency & Percentage & Effective percentage & Cumulative percentage \\
\hline Effective Zhuang & 39 & 23.5 & 23.6 & 23.6 \\
\hline Han & 109 & 65.7 & 66.1 & 89.7 \\
\hline Yao & 9 & 5.4 & 5.5 & 95.2 \\
\hline Hui & 1 & 0.6 & 0.6 & 95.8 \\
\hline Yankee & 2 & 1.2 & 1.2 & 97.0 \\
\hline Tibetan & 1 & 0.6 & 0.6 & 99.4 \\
\hline Dong & 3 & 1.8 & 1.8 & 100.0 \\
\hline Miao & 1 & 0.6 & 0.6 & \\
\hline Total & 165 & 99.4 & 100.0 & \\
\hline Defect System & 1 & 0.6 & & \\
\hline Total & 166 & 100.0 & & \\
\hline
\end{tabular}

2. The education level characteristics of samples

We investigated through the $\mathrm{G}$ school teaching committee in each class to send a questionnaire survey. 166 valid questionnaires were recovered. The students who filled in the questionnaire included social work undergraduate students, as well as master of social work [6].

Table 2. The education level of samples

\begin{tabular}{|c|c|c|c|c|}
\hline & Frequency & Percentage & Effective percentage & Cumulative percentage \\
\hline Effective Undergraduates & 148 & 89.2 & 89.2 & 89.2 \\
\hline Graduates & 18 & 10.8 & 10.8 & 100.0 \\
\hline Total & 166 & 100.0 & & \\
\hline
\end{tabular}

From the above table, it can be seen that, in the 166 samples, there were 148 undergraduates in the social work major who filled the questionnaire, accounting for $89.2 \%$; there were 18 social work major masters, accounting for $10.8 \%$ [7]. What needs to be illustrated is that G school social work major masters were about 36 , and those who filled the questionnaire were 18, accounting for about $50 \%$ of the total number of $\mathrm{G}$ school social work masters. 


\subsection{Analysis of the dilemma faced by the development of national social work education: a case study of G school}

1. Weak teachers forces of social work education, difficult to solve at once

From G school 164 valid samples, it is found that, 106 people know that some professional teachers teach them are from minority areas, accounting for $63.9 \%$ of the total number of samples [8]. It suggested that students usually had a better understanding of the national composition of the teachers.

Table 3. Are there teachers from minority areas in the teachers who teach you?

\begin{tabular}{|c|c|c|c|c|}
\hline & Frequency & Percentage & Effective percentage & Cumulative percentage \\
\hline Effective Yes & 106 & 62.9 & 64.6 & 64.6 \\
\hline No & 55 & 33.1 & 33.5 & 98.2 \\
\hline Don't know & 3 & 1.8 & 1.8 & 100.0 \\
\hline Total & 164 & 98.8 & 100.0 & \\
\hline Defect System & 2 & 1.2 & & \\
\hline Total & 166 & 100.0 & & \\
\hline
\end{tabular}

2. Poor national consciousness of parts of social work professional students

First of all, a considerable number of social work major students in $\mathrm{G}$ school have a poor sense of nationality. Through the analysis of 166 samples, it is found that, in the 164 valid samples, there are 157 people said that they have ethnic minority students, accounting for $94.6 \%$ of the total number of samples; there are 7 people said that they have no minority students. According to the common sense, in the daily life, minority nation students, in the acceptance of social work education, should slowly cultivate their national sensitivity or cultural sensitivity [9]. But in fact, we found that there are 7 people said that they do not have the minority nation students, while actually, their classmates are indeed minority nation students, but they basically do not have this awareness.

Similarly, in the investigation of "Are there minority nation teachers in the professional teachers who teach you?", there are 55 people said that there is no minority nation teachers in their teachers, and 3 people said that they do not know. In fact, in $\mathrm{G}$ school, the social work professional teachers include teachers from the nation of Zhuang, Yao and Naxi. Generally speaking, there are a total of 58 people being not sensitive to their own ethnic composition of teachers [10].

Secondly, a considerable proportion of $\mathrm{G}$ school social work professional students do not agree with the national social work courses. In the surveyed 166 students in social work in G school, there are 147 people said that it is necessary to set up national curriculum; 19 people said that "There is no need for social work profession to open the national courses", accounting for $11.4 \%$ of the total sample. G school is located in ethnic minority areas, belonging to ethnic autonomous areas. There are still many Countries Poverty-stricken Counties in ethnic minority areas; and in the survey, 94.6\% of respondents said that they have minority students. While, what is surprising is that $11.4 \%$ of people said that there is no need to set up national courses.

3. Situation of practice separating from the teaching links, remained to be substantially improved

The research found that, on the one hand, G school set up "Chinese Ethnics Introduction", "National Sociology", "Chinese Culture Introduction" and so on courses for undergraduate students, "National Social Work" and other national curriculum for the master of social work major [11]. However, in students practice and link in $\mathrm{G}$ school, there are basically no national class practice units, resulting in the separation of practice and teaching environment.

Table 4. What are the best teaching methods for nation social work related courses?

\begin{tabular}{|c|c|c|c|c|}
\hline & Frequency & Percentage & $\begin{array}{l}\text { Effective } \\
\text { percentage }\end{array}$ & $\begin{array}{l}\text { Cumulative } \\
\text { percentage }\end{array}$ \\
\hline Effective Classes combined with practice & 50 & 30.1 & 30.9 & 30.9 \\
\hline Practice & 97 & 58.4 & 59.9 & 90.7 \\
\hline Class learning & 14 & 8.4 & 8.6 & 99.4 \\
\hline Have no idea & 1 & 0.6 & 0.6 & 100.0 \\
\hline Total & 162 & 97.6 & 100.0 & \\
\hline Defect System & 4 & 2.4 & & \\
\hline Total & 166 & 100.0 & & \\
\hline
\end{tabular}


On the other hand, we found after the analysis of 164 valid samples that, there are 50 people thinking that the best teaching methods for nation social work related courses is "class combined with practice", accounting for $30.1 \%$ of the total sample; 97 people think that it is "practice", accounting for $59.4 \%$ of the total sample; 4 people think that it is "classroom learning"; and there are 1 people having no idea.

\section{Countermeasures and suggestions for promoting the development of national social work education in China}

\subsection{In academic education and continuing education, pay attention to the training of minority social workers}

First of all, it is proposed that, the Ministry of Civil Affairs and the Ministry of Education should jointly issue related policies and documents for the relevant training of minority social workers. For instance, implement the Chinese national social work education pilot units and disburse related funds. It is also suggested that, Chinese Association for Social Work Education and Chinese Social Work Education Steering Committee formulate and review the standards and norms of national social work education [12]. What's more, it is supposed to guide the related colleges and universities to increase the intensity of training of ethnic minority social workers.

Secondly, reduce the requirements for national minority to participate in social work education and vocational qualification examination, and increase the support of minority nationality academic education and vocational qualification examination.

Finally, we will accelerate the development and support of academic education and continuing education units for ethnic minority's social workers in China. Firstly, determine and support a number of ethnic minority social workers cultivation base; secondly, quickly establish and support a number of teams and units where the minority social workers engaged in.

\subsection{Attach importance to the cultivation of national social work education team and the development of teaching materials and courses}

First of all, the relevant state departments should attach importance to the cultivation and development of minority social work education teams. Through independent reporting, project support and so on, it is necessary to create a cross disciplinary and cross national school social work team for the education, and even jointly cooperate with Hong kong, Taiwan and other related social work institutions.

Secondly, in view of the fact that our country has a large number of ethnic groups, we can guide the cultivation and development of social work education and research teams of different nationalities or ethnic groups, such as Tibetan social work or the cultivation of Tibetan society. Build Zhuang social work or community work in Zhuang nationality research and education team cultivation, social work and the Muslim Hui community social workers, and even the team building of social work on religion [13]. Moreover, make the research and education of national social work from the macroscopic and abstract national level to the specific national or ethnic community level.

Thirdly, the state should guide and cultivate a number of national social work teaching materials, curriculum development and cultivation.

\subsection{Pay attention to the effective cohesion and interaction of national social work research, education and practice}

On the one hand, the research, especially the practical research, will bring rich cases and theoretical knowledge for the national social work education. For this, the State Ethnic Affairs Commission, the Ministry of Civil Affairs, the Provincial Association of Social Sciences, Ministry of Education and the National Philosophy and Social Sciences should, in the future fund projects, add the research guidance with the theme of national social work, and incline to funding related projects. On the other hand, the Ministry of Civil Affairs, Ministry of Education and the China Association for Social Work Education Cooperation, make a statistic of colleges and universities social work curriculum and training plan, minority students and teachers, internships and project, and understand the current situation, so as to make a scientific decision on this basis. Thirdly, the National Social Work Talent 
Cultivation colleges and universities or units can develop related units of Nationalities Committee, United Front Work Department and Ethnic Regions as a practice platform.

\subsection{Speed up the construction of the top level system of ethnic social work education}

Firstly, it is proposed to amend the Law on Ethnic Regional Autonomy and increase the construction of national social work personnel, national social work research and education, innovation of ethnic working modes and so on. Secondly, introduce "Social Work Law" as soon as possible, make constraints for social work, national social work and so on concepts, and improve the social work qualification and continuing education. Thirdly, introduce various types of procedures or documents as soon as possible, such as "Minority National Social Work Talents Training and Development Methods" [14], to regulate and clarify minority teachers and students, teaching materials, curriculum, and social position and so on. Fourth, revise relevant provisions of social occupation qualification. For the contents of the syllabus, textbooks, and papers, it is necessary to arrange a certain proportion of ethnic or multicultural themes, to better cultivate ethnic and cultural sensitivity of social workers.

\section{Conclusion}

National social work practice and research in China is in its infancy. National social work, as a field of social work or an interdisciplinary subject, has not yet entered the mainstream practice or academic circles, which needs to attract more people's attention. In this paper, the research on the social work education of ethnic groups is expected to enrich the localization of social work in China, especially the localization of social work education. Based on the investigation of G school, it is found that national social work education has the following difficulties: national social work education is weak, difficult to solve soon; part of social work students' national consciousness is poor and they think that there is no need to set up national curriculum; national social work education practice and teaching are separated, unable to make an improvement suddenly; national social work teaching materials cannot be paid enough attention to, no substantive progress. For solving these problems, several suggestions are given: in academic education and continuing education, pay attention to the training of minority social workers; attach importance to the cultivation of national social work education team and the development of teaching materials and courses; pay attention to the effective cohesion and interaction of national social work research, education and practice; and speed up the construction of the top level system of ethnic social work education. Through the implementation of above proposals, the problems can be well solved, and national social work education will get a better and further development.

\section{References}

[1]. Crabtree-Nelson, S., Grossman, S. F., \& Lundy, M. (2016). A Call to Action: Domestic Violence Education in Social Work. Social Work.

[2]. Dedotsi, S., Young, A., \& Broad Hurst, K. (2016). Social work education in a time of national crisis in Greece: educating the workforce to combat inequalities. European Journal of Social Work, 19(3-4), 368-384.

[3]. Levy, S., Aiton, R., Doig, J., Dow, J. P., Brown, S., Hunter, L., \& McNeil, R. (2016). Outcomes focused user involvement in social work education: applying knowledge to practice. Social Work Education, 35(8), 866-877.

[4]. Inch, E. (2016). Are you ready? Qualifying social work students' perception of their preparedness to work competently with service users from sexual and gender minority communities. Social Work Education, 1-18. 
[5]. Jani, J. S., Osteen, P., \& Shipe, S. (2016). Cultural Competence and Social Work Education: Moving Toward Assessment of Practice Behaviors. Journal of Social Work Education, 52(3), 311-324.

[6]. Watkinson, A. M., \& Rock, L. (2016). Child physical punishment and international human rights: Implications for social work education. International Social Work, 59(1), 86-98.

[7]. Goossen, C., \& Austin, M. J. (2016). Service user involvement in UK social service agencies and social work education. Journal of Social Work Education, 1-15.

[8]. Hollander, R., Amekudzi-Kennedy, A., Bell, S., Benya, F., Davidson, C., Farkos, C., \& Quigley, D. (2016). Network priorities for social sustainability research and education: Memorandum of the Integrated Network on Social Sustainability Research Group. Sustainability: Science, Practice, \& Policy, 12(1).

[9]. Han, M., Nguyen, D., Cohen, E., Drabble, L., Nguyen, H., Sen, S., \& Tran, T. (2016). Exploring the Transferability of Competency-Based Education Model to Social Work Education in Vietnam. Social Work Education, 35(6), 659-671.

[10]. Han, M., Nguyen, D., Cohen, E., Drabble, L., Nguyen, H., Sen, S., \& Tran, T. (2016). Exploring the Transferability of Competency-Based Education Model to Social Work Education in Vietnam. Social Work Education, 35(6), 659-671.

[11]. Sherraden, M., Birkenmaier, J., McClendon, G. G., \& Rochelle, M. (2016). Financial Capability and Asset Building in Social Work Education: Is It "The Big Piece Missing?". Journal of Social Work Education, 1-17.

[12]. Beresford, P., Casey, H., \& Macdonough, J. (2016). 3.3 England: Gap-Mending: Developing a New Approach to User and Carer Involvement in Social Work Education. The Service User as a Partner in Social Work Projects and Education: Concepts and Evaluations of Courses with a Gap-Mending Approach in Europe, 69.

[13]. Begun, S., Bird, M., Ramseyer Winter, V., Massey Combs, K., \& McKay, K. (2016). Correlates of Social Work Students' Abortion Knowledge and Attitudes: Implications for Education and Research. Social work in public health, 31(4), 276-287.

[14]. Netting, F. E., O’Connor, M. K., Cole, P. L., Hopkins, K., Jones, J. L., Kim, Y., ... \& Weil, M. O. (2016). Reclaiming and reimagining macro social work education: A collective biography. Journal of Social Work Education, 52(2), 157-169. 